\title{
Perspectives for Wearable Electronics in Healthcare and Childcare
}

\author{
Johanna Virkki ${ }^{1}$, Pasi Raumonen ${ }^{2}$ \\ ${ }^{1}$ Department of Electronics and Communications Engineering, Tampere University of Technology, Tampere, Finland \\ ${ }^{2}$ Department of Mathematics, Tampere University of Technology, Tampere, Finland \\ Email: johanna.virkki@tut.fi
}

Received June 3, 2013; revised July 8, 2013; accepted July 31, 2013

Copyright (C 2013 Johanna Virkki, Pasi Raumonen. This is an open access article distributed under the Creative Commons Attribution License, which permits unrestricted use, distribution, and reproduction in any medium, provided the original work is properly cited.

\begin{abstract}
This paper starts with a literature survey that introduces the possibilities of wearable electronics (WE) in different health-care and childcare applications. Next, 24 personal interviews and an Internet forum survey were conducted in Finland about the use of WE in the applications mentioned above. According to the results, most of the people feel positive about clothes used for wireless identification purposes in healthcare and childcare, but when more information about the person is added that can be wirelessly read, the feelings become more negative. Several important points to consider before implementation of WE for healthcare and childcare environments were brought up.
\end{abstract}

Keywords: Childcare; Finland; Healthcare; Individual Privacy; Wearable Electronics

\section{Introduction}

One important part of the development of the future living environment is the development of wearable electronics (WE) [1,2]. Recently, many innovative products have appeared and expectations about the potential of WE are high. The history of WE is summarized in [3]. Important application areas can be found e.g. from healthcare $[4,5]$ and childcare.

This study focuses on WE used in healthcare and childcare environments. It includes a literature survey, personal interviews in Finland, and an Internet forum survey in Finnish Internet forums. After this introduction to the literature survey, the second section introduces the interviews and the Internet forum survey. The results are presented and discussed in the third section. The last section summarizes the results and presents the conclusions of this paper.

\subsection{WE in Healthcare}

In healthcare applications, WE can be used e.g. in patient monitoring, positioning, and identification in hospitals [6]. For example, a wireless sensor network (WSN)based indoor location system to support the nursing staff [7], a radiofrequency identification (RFID) system to track and identify patients in a children's critical care ward [8], body-worn tags for the continuous tracking of human movements in a conventional room [9], and a system to detect life-threatening changes of daily activeties of older people [10] have been presented. In the future, the importance of telemedicine and home-nursing is expected to grow. The adjustment of the healthcare systems to the increasing number of elderly and patients with chronic diseases is one of the biggest challenges to the European Union, including Finland, where this survey was done, and the future of the public healthcare is currently a hot topic in the Finnish media. There are many opportunities to help elders live alone in their homes with the help of WE. For example, a system has been proposed that is installed in footwear for location tracking and in gloves for activity monitoring [11], as well as an RFID-based fall detection monitoring system that includes a dual-band RFID module, placed into a pair of slippers [12]. WE allows the body status to be monitored by devices that measure heart or brain activity, blood pressure, body temperature, or other body functions [13]. For example, the realization of wireless oxygen saturation and heart rate system for patient monitoring [14], a scheme for monitoring the patient's temperature, heartbeat, and pressure [15], and a wearable health system for non-invasive and wireless monitoring of physiological signals [16] have been introduced. Free- 
dom of movement achieved by WE is especially important in home nursing [17]. Thus, another application for WE is in the recovery of patients after an operation; instead of being hospitalized for recovery monitoring, the patients can be discharged to return home sooner. In addition to reducing the cost of the operation, home-nursing can increase the patient's physical activity, and thus also speed up recovery.

\subsection{WE in Childcare}

In childcare applications, WE could automate the children security and safety and thus provide help to nurses [18]. A single cloth can keep the information of a child (e.g. name, age, kindergarten group, allergies, etc.) easily achieved for the nurses. In one proposed system, RFID tags were embedded in the children uniforms in order to automate the children security supervision and to provide integration with the current security management system for the kindergarten [19]. Another study proposed a system solution based on RFID to be deployed in schools. The system registers arrival and departure times of pupils and sends that information to parents via SMS and/or e-mail [20]. In Finland, all children under seven years old have the right to have daycare organized by municipalities either on a full-time or part-time basis. Compulsory education starts in the year when a child becomes seven years of age and in the previous year the child can participate in pre-primary education in a pre-primary school.

\subsection{Individual Privacy and WE}

One of the most important challenges in convincing users to adopt WE is the protection of privacy. Informational privacy is the right of an individual to exercise control over the collection, use, disclosure, and retention of his or her personal information. Concerns over privacy can spread wide, particularly as wireless systems can track users' actions, behavior, and on-going preferences [21, 22]. It makes the adoption of a ubiquitous healthcare or childcare system deterred [23,24]. It has been stated, however, that privacy problems are not caused by the technology alone, but primary through activities of people, businesses, and governments [25].

Several interesting surveys have already been conducted. According to one study, using an iPod jacket as the test item, the most important adoption factors are convenience and compatibility, and the least important are perceived social prestige and observability [26]. It was mentioned, that this finding might not be intuitive, considering that potential consumers of this kind of WE are thought to be greatly influenced by external forces such as peer pressure, trends, and perceived social prestige. In a survey focusing on the activities and habits that people do at home, which they would not want to be re- corded, the bedroom was found to be the most private place [27]. The willingness of older adults to share health or activity data with one's doctor or family members and concerns about privacy or security of monitoring has also been measured [28]. A high proportion (over 72\%) of participants reported acceptance of in-home and computer monitoring and willingness to have data shared with their doctor or family members. However, a majority (60\%) reported concerns related to privacy or security; these concerns increased after one year of participation. Findings suggest that involvement in this unobtrusive in-home monitoring study may have raised awareness about the potential privacy risks of technology. Elderly individuals, who were still living independently, were asked to discuss their perceptions and concerns towards the likelihood of using a WSN-based healthcare system in their home [29]. The findings in this study indicate that independence is highly valued by elderly people and hence any system or technology that can prolong that independence tends to be highly regarded. Thus, for example the privacy of WSN health data might not be as important as typically considered. Also, according to the participants in a similar study, the results suggested strong acceptance of the concept of home health monitoring and the devices to make the system work [30]. In a study, where opinions on individual privacy were collected from China and Finland, the Internet of Things applications related to personal health were the least worrying ones among all applications [31]. It was stated, that in healthcare, the most important thing is that all the vital information is available when needed. This work shares some similar objects to the studies above. The goal is to gather information on ordinary people's thoughts about WE in healthcare and childcare in Finland.

\section{Interviews and Internet Forum Survey}

\subsection{Interviews}

In this work, 24 Finnish people of different age were interviewed (genders and ages of the answerers can be seen in Table 1). The personal interviews were conducted by an associate of the researcher, and they took place either at the answerers working facility, home, or at a neutral, public place. Some of the interviews were done by private (e-)mails between the researcher and the answerers. All these interviews thus had more flexibility than only a paper survey as both the researcher and the answerer were able to ask for clarification. In this study, the individual privacy refers to the evolving relationship between the technology and the legal right to, or public expectation of, privacy in the collection and sharing of data about one's self. The interview had the following questions and a chance for free comments.

1) Would you be willing to wear hospital clothes that. 
Table 1. Genders and ages of the interviewees.

\begin{tabular}{ccc}
\hline & female & male \\
\hline minimum age & 29 & 28 \\
average age & 36 & 38 \\
maximum age & 52 & 61 \\
number of interviewees & 12 & 12 \\
\hline
\end{tabular}

1A) Would allow wireless reading of your name and patient number for those taking part into your care? (Yes/No)

1B) In addition to wireless reading of your name and patient number, would allow wireless reading of your medical and medication records for those taking part into your care? (Yes/No)

2) How worried would you be about your individual privacy in situations $1 \mathrm{~A}$ and $1 \mathrm{~B}$ ? $($ Scale $=1-5$, where 1 $=$ not worried at all, $5=$ very worried)

3) Would you be willing to let your child wear clothes in kindergarten that.

3A) would allow the nurses to wirelessly read the child's name and kindergarten group? (Yes/No)

3B) In addition to the child's name and kindergarten group, would allow the nurses to wirelessly read other information, such as age, allergies, legal guardian, or contact information of guardians? (Yes/No)

4) How worried would you be about your child's individual privacy in situations $3 \mathrm{~A}$ and $3 \mathrm{~B}$ ? (Scale $=1-5$, where $1=$ not worried at all, $5=$ very worried)

\subsection{Internet Forum Survey}

The second part of this work was a survey of discussions on different Internet forums. Discussions on WE were started in May 2013, on 7 Finnish Internet forums, where people are able to discuss anonymously. Three of the forums were focused on discussions on parenthood and children, two of the forums were science forums, one was a forum concentrated on electronics, and one for media and information technology. In the message starting the discussion, the potential of WE in healthcare and childcare was introduced and thoughts of such topic were asked. The goal was to collect a general idea of feelings and highlight some of the presented thoughts.

\section{Results and Discussion}

\subsection{Results from Interviews}

The results (percentages for answers "yes" and "no") from the questions $1 \mathrm{~A}, 1 \mathrm{~B}, 3 \mathrm{~A}$, and $3 \mathrm{~B}$ can be seen in Table 2. The results for how worried would the interviewees be about the individual privacy in these different situations can be seen in Table 3 and Figure 1.
Table 2. The results (percentages for answers "yes" and “no") from the situations $1 \mathrm{~A}, 1 \mathrm{~B}, 3 \mathrm{~A}$, and $3 \mathrm{~B}$.

\begin{tabular}{|c|c|c|c|c|c|}
\hline & yes/no & 1A & 1B & 3A & $3 B$ \\
\hline \multirow[t]{2}{*}{ female (\%) } & Yes & $\begin{array}{c}75 \\
(\mathrm{~N}=9)\end{array}$ & $\begin{array}{c}50 \\
(\mathrm{~N}=6)\end{array}$ & $\begin{array}{c}83 \\
(\mathrm{~N}=10)\end{array}$ & $\begin{array}{c}8 \\
(\mathrm{~N}=1)\end{array}$ \\
\hline & No & $\begin{array}{c}25 \\
(\mathrm{~N}=3)\end{array}$ & $\begin{array}{c}50 \\
(\mathrm{~N}=6)\end{array}$ & $\begin{array}{c}17 \\
(\mathrm{~N}=2)\end{array}$ & $\begin{array}{c}92 \\
(\mathrm{~N}=11)\end{array}$ \\
\hline \multirow[t]{2}{*}{ male (\%) } & Yes & $\begin{array}{c}83 \\
(\mathrm{~N}=10)\end{array}$ & $\begin{array}{c}33 \\
(N=4)\end{array}$ & $\begin{array}{c}83 \\
(\mathrm{~N}=10)\end{array}$ & $\begin{array}{c}50 \\
(\mathrm{~N}=6)\end{array}$ \\
\hline & No & $\begin{array}{c}17 \\
(\mathrm{~N}=2)\end{array}$ & $\begin{array}{c}67 \\
(\mathrm{~N}=8)\end{array}$ & $\begin{array}{c}17 \\
(\mathrm{~N}=2)\end{array}$ & $\begin{array}{c}50 \\
(\mathrm{~N}=6)\end{array}$ \\
\hline \multirow[t]{2}{*}{ all (\%) } & Yes & $\begin{array}{c}79 \\
(\mathrm{~N}=19)\end{array}$ & $\begin{array}{c}42 \\
(\mathrm{~N}=10)\end{array}$ & $\begin{array}{c}83 \\
(\mathrm{~N}=20)\end{array}$ & $\begin{array}{c}29 \\
(\mathrm{~N}=7)\end{array}$ \\
\hline & No & $\begin{array}{c}21 \\
(\mathrm{~N}=5)\end{array}$ & $\begin{array}{c}58 \\
(\mathrm{~N}=14)\end{array}$ & $\begin{array}{c}17 \\
(\mathrm{~N}=4)\end{array}$ & $\begin{array}{c}71 \\
(\mathrm{~N}=17)\end{array}$ \\
\hline
\end{tabular}

Table 3. The average values of results how worried would the interviewees be about the individual privacy in situations 1A, 1B, 3A, and 3B, scale 1 - 5 .

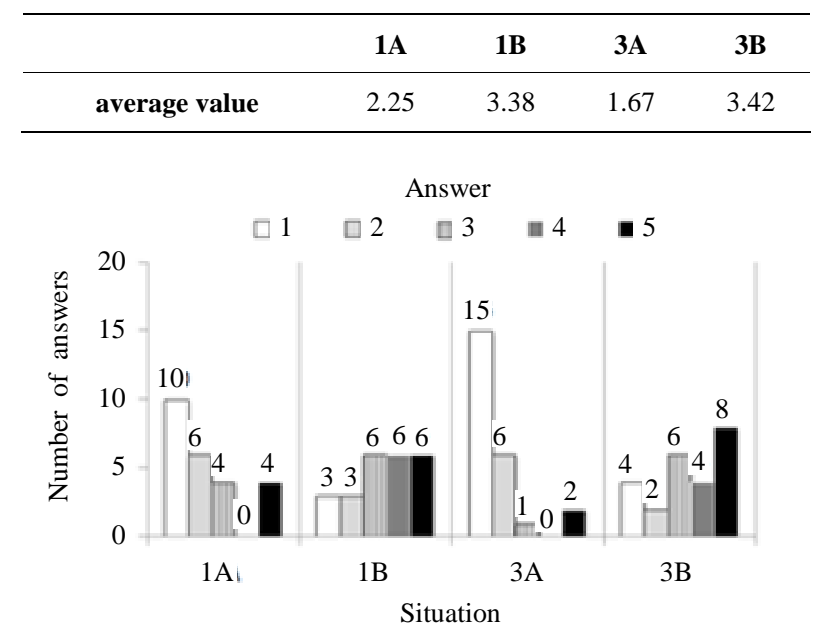

Figure 1. The results how worried would the interviewees be about the individual privacy in situations $1 \mathrm{~A}, 1 \mathrm{~B}, 3 \mathrm{~A}$, and $3 B$, scale 1 - 5 .

According to our results, $79 \%$ of the interviewees would be willing to wear hospital clothes that would allow wireless reading of their name and patient number (Situation 1A). If, in addition of wireless reading of the name and patient number, the hospital clothes would allow wireless reading of medical and medication records (Situation 1B), only $42 \%$ would be willing to wear the clothes. In free comments, WE in hospitals were mostly considered useful, especially in hospitals with a lot of patients and a great turnover, as such clothes may prevent mix-ups of patients. However, it was strongly pointed out that the use of this kind of clothes should be voluntary or there would have to be a good reason for it. It was specified that availability of medical records is good but they cannot be available for inappropriate people, not even for those working in that hospital.

As can be seen in Table 3, on scale 1 - 5, the average values for the worry about individual privacy in situa- 
tions $1 \mathrm{~A}$ and $1 \mathrm{~B}$ were 2.25 and 3.38 , respectively. Thus, as natural, when more information on the user of the clothes is available, the worry about the individual privacy is stronger. However, in neither situation, the worry cannot be considered extremely strong (scale 1 - 5).

It is shown in Table 2, that $83 \%$ of the interviewees would be willing to let their child wear clothes in kindergarten that would allow the nurses to wirelessly read the child's name and kindergarten group (Situation 3A). If, in addition to the child's name and kindergarten group, the clothes would allow the nurses to wirelessly read other information, such as age, allergies, legal guardian, contact information of guardians (Situation 3B), only $29 \%$ would be willing to let their child wear the clothes. In situation $3 \mathrm{~B}$, there was a notable difference between women and men; only $8 \%$ of the answers from women were positive, compared to $50 \%$ from men. The suitability of WE for children was questioned in many ways in free comments. It was mentioned, that if children are able to rip an electronic component from the clothes, they may eat it, which may cause a serious danger. It was also pointed out, that with children, it is essential that the caregivers should know all children in person. Since this is not always possible, this kind of wearable safety was seen to be one kind of solution.

As can be seen in Table 3, on scale 1 - 5, the average numbers for the worry about individual privacy in situations 3A and 3B were 1.67 and 3.42, respectively. Thus, WE that allow the name and kindergarten group to be wirelessly read were not found to be a threat for individual privacy of the child. There were no free comments related to individual privacy of WE in kindergartens, but according to the result 3.42 (on scale 1 - 5) from situation $3 \mathrm{~B}$, at least some worrying issues were considered when more information was available for wireless reading.

Due to the small amount of the interviewees, this survey does not offer statistical data for conclusions. However, this paper gives a starting point for research on this important topic by gathering different perspectives for WE in healthcare and childcare. Future research will involve significantly more answerers in order to achieve more meaningful results.

\subsection{Results from Internet Forum Survey}

The first thing that was noticed when starting conversations on different Internet forums was that it is hard to start conversation on WE, as the topic did not enjoy a great interest. 2 of the 7 started conversations got no answers at all. However, in 5 of them, interesting thoughts were presented.

In most of the started conversations, the idea of using WE in hospitals and kindergartens, as long as it is done with the person's own permission, was seen promising. It was also brought up that such applications already exist; particularly tracers for children were mentioned. On the contrary, in one conversation it was stated that WE will never become a part of everyday life. Reasons for this were, e.g., the fact that people want to change clothes all the time and all clothes would need to have the same information stored in them. Also, it was stated that no electronic component can monitor who actually eats the delivered drugs. In addition, WE in healthcare were found to be the sad future direction mainly because there is not enough staff working in hospitals.

Also, the mixing of clothes (e.g. of patients in the same room) must be prevented, as it was mentioned in one conversation. This may also cause care in a kindergarten, where clothes get easily mixed-up. Thus, instead of preventing mix-ups, WE could cause them. The effects of continuous washing and bending on electronics were considered. This is reasonable, since the reliability of wearable components, e.g. in hospitals, is essential.

It was also discussed that some people may not be willing to wear clothes with electronics, as is currently the case with safety wristbands. It was also pointed out that clothes could be taken off. Thus, for example a lockable band was considered to be more suitable if monitoring is mandatory for some reason. In addition, the problems with drawing the limits were mentioned; at what point we can start to monitor a demented person without him/her knowing and how young/old child can decide if not to wear clothes with electronics. In one conversation, the use of current electronic devices, e.g. mobile phones, to be utilized in such healthcare applications was also considered. Current mobile devices already have many of the needed features. In many cases, existing mobile devices could be used instead of WE.

\section{Conclusions}

Many innovative applications of WE have appeared recently and expectations about the possibilities are great. WE have an important application area in the healthcare industry and also a great potential for applications in kindergarten and primary school environments. This paper offers information on ordinary people's thoughts to those developing wearable electronic applications and those working with the individual privacy in the future wireless world. It introduces a literature survey about the possibilities of WE in healthcare and childcare. In addition, 24 personal interviews and an Internet forum survey were conducted about these applications in Finland.

According to the results, most of the people feel positive about clothes used for wireless identification purposes. However, when more information is added which can be wirelessly read, the feelings become more negative. In general, the use of WE in hospitals and kinder- 
gartens, as long as it is done with person's own permission, was seen promising. Several important points to consider were brought up in free comments and in the Internet forum survey, e.g., related to the safety of children, individual privacy of people, practical issues to consider when embedding electronics to clothes, and usability of already existing mobile devices for such future applications.

\section{REFERENCES}

[1] T. Löher, R. Vieroth, M. Seckel, A. Ostmann and H. Reichl, "Stretchable Electronic Systems for Wearable and Textile Applications,” IEEE VLSI Packaging Workshop of Japan, Kyoto, 1-2 December 2008, pp. 9-12.

[2] M. Swan, "Sensor Mania! The Internet of Things, Wearable Computing, Objective Metrics, and the Quantified Self 2.0.," Journal of Sensor and Actuator Networks, Vol. 3, No. 1, 2012, pp. 217-253. doi:10.3390/jsan1030217

[3] H.-J. Yoo, "Your Heart on Your Sleeve: Advances in Textile-Based Electronics Are Weaving Computers Right into the Clothes We Wear," IEEE Solid-State Circuits Magazine, Vol. 5, No. 1, 2013, pp. 59-70. doi:10.1109/MSSC.2012.2232781

[4] L. Yang, R. Vyas, A. Rida, J. Pan and M. M. Tentzeris, "Wearable RFID-Enabled Sensor Nodes for Biomedical Applications," Electronic Components and Technology Conference, Lake Buena Vista, 27-30 May 2008, pp. 2156-2159.

[5] H. Alemdar and C. Ersoy, "Wireless Sensor Networks for Healthcare: A Survey,” Computer Networks, Vol. 54, No. 15, 2010, pp. 2688-2710. doi:10.1016/j.comnet.2010.05.003

[6] S.-W. Wang, W.-H. Chen, C.-S. Ong, L. Liu and Y.-W. Chuang. "RFID Application in Hospitals: A Case Study on a Demonstration RFID Project in a Taiwan Hospital," International Conference on System Sciences, Vol. 8, 4-7 January 2006, 10 p. doi:10.1109/HICSS.2006.422

[7] C. C. Hsiao, Y-J. Sung, S.-J. Lau; C.-H. Chen, F.-H. Hsiao, H.-H. Chu and P. Huang, "Towards Long-Term Mobility Tracking in NTU Hospital's Elder Care Center,” IEEE International Conference on Pervasive Computing and Communications Workshops, Seattle, 21-25 March 2011, pp. 649-654.

[8] E. Iadanza and F. Dori, "Custom Active RFID Solution for Children Tracking and Identifying in a Resuscitation Ward," IEEE International Conference, Engineering in Medicine and Biology, Minneapolis, 3-6 September 2009, pp. 5223-5236.

[9] C. Occhiuzzi, S. Cippitelli and G. Marrocco, "Modeling, Design and Experimentation of Wearable RFID Sensor Tag," IEEE Transactions on Antennas and Propagation, Vol. 58, No. 8, 2010, pp. 2490-2498. doi:10.1109/TAP.2010.2050435

[10] A. A. Safavi, A. Keshavarz-Haddad, S. Khoubani, S. Mosharraf-Dehkordi, A. Dehghani-Pilehvarani and F. S. Tabei, "A Remote Elderly Monitoring System with Localizing Based on Wireless Sensor Network," Interna- tional Conference on Computer Design and Applications, Qinhuangdao, 25-27June 2010, pp. V2-553-V2-557.

[11] K. K. Jung, D. S. Son and K. H. Eom, "RFID Footwear and Floor System," World Congress on Computer Science and Information Engineering, Los Angeles, 31 March-2 April 2009, pp. 72-75.

[12] Y.-C. Chen and Y.-W. Lin, "Indoor RFID Gait Monitoring System for Fall Detection,” International Symposium on Aware Computing, Tainan, 1-4 November 2010, pp. 207-212.

[13] Z. Pang, Q. Chen, L. Zheng and E. Dubrova, “An InHome Medication Management Solution Based on Intelligent Packaging and Ubiquitous Sensing,” International Conference on Advanced Communication Technology, PyeongChang, 27-30 January 2013, pp. 545-550.

[14] C. Rotariu and V. Manta, "Wireless System for Remote Monitoring of Oxygen Saturation and Heart Rate,” Federated Conference on Computer Science and Information Systems, Wroclaw, 9-12 September 2012, pp. 193-196.

[15] B. Vijayalakshmi and C. Ram Kumar, "Patient Monitoring System using Wireless Sensor based Mesh Network," International Conference on Computing Communication \& Networking Technologies, Coimbatore, 26-28 Junly 2012, pp. 1-6.

[16] R. G. Haahr, S. Duun, E. V. Thomsen, K. Hoppe and J. Branebjerg, "A Wearable 'Electronic Patch' for Wireless Continuous Monitoring of Chronically Diseased Patients," International Summer School and Symposium on Medical Devices and Biosensors, Hong Kong, 1-3 June 2008, pp. 66-70.

[17] T. Kellomäki, W. G. Whittow, J. Heikkinen and L. Kettunen, "2.4 GHz Plaster Antennas for Health Monitoring,” European Conference on Antennas and Propagation, Berlin, 23-27 March 2009, pp. 211-215.

[18] C.-J. Lin, T.-L. Lee, S.-L. Syu and B.-W. Chen, “Application of Intelligent Agent and RFID Technology for Indoor Position: Safety of Kindergarten as Example,” International Conference on Machine Learning and Cybernetics, Qingdao, 11-14 July 2010, pp. 2571-2576.

[19] Z. Fang, L. Wei, W. Chen and Y. He, “A RFID-Based Kindergarten Intelligence Security System,” IEEE International Conference on e-Business Engineering, Hangzhou, 9-11September 2012, pp. 321-326.

[20] M. Krsmanovic, G. Muric and N. Gospic, "Improvement of Children Safety by using RFID Based Service,” Telecommunications Forum, Belgrade, 22-24 November 2011, pp. 130-133.

[21] H. Feng and W. Fu, "Study of Recent Development about Privacy and Security of the Internet of Things," International Conference on Web Information Systems and Mining, Sanya, 23-24 October 2010, pp. 91-95.

[22] S. Kurkovsky, E. Syta and B. Casano, "Continuous RFIDEnabled Authentication: Privacy Implications,” IEEE Technology and Society Magazine, Vol. 30, No. 3, 2011, pp. 34-41. doi:10.1109/MTS.2011.942306

[23] W. J. Song, S. H. Son, M. Choi and M. Kang, "Privacy and Security Control Architecture for Ubiquitous RFID Healthcare System in Wireless Sensor Networks,” Inter- 
national Conference on Consumer Electronics, Las Vegas, 7-11 January 2006, pp. 239-240.

[24] S. S. Choi, M. K. Choi, W. J. Song and S. H. Son, "Ubiquitous RFID Healthcare Systems Analysis on PhysioNet Grid Portal Services Using Petri Nets,” International Conference on Information, Communications and Signal Processing, Bangkok, 6-9 December 2005, pp. 1254-1258.

[25] D. J. Solove, “A Taxonomy of Privacy,” University of Pennsylvania Law Review, Vol. 154, No. 3, 2006, GWU Law School Public Law Research Paper No. 129.

[26] G. Anderson and G. Lee, "Why Consumers (Don't) Adopt Smart WE," IEEE Pervasive Computing, Vol. 7, No. 3, 2008, pp. 10-12. doi:10.1109/MPRV.2008.64

[27] E. K. Choe, S. Consolvo, J. Jung, B. Harrison and J. A. Kientz, "Living in a Glass House: A Survey of Private Moments in the Home," International Conference on Ubiquitous Computing, Beijing, 17-21 Sseptember 2011, pp. 41-45.
[28] L. Boise, K. Wild, N. Mattek, M. Ruhl, H. H. Dodge and J. Kaye, "Willingness of Older Adults to Share Data and Privacy Concerns after Exposure to Unobtrusive In-Home Monitoring,” Gerontechnology, Vol. 11, No. 3, 2013, pp. 428-435.

[29] R. Steele, A. Lo, C. Secombe and Y. K. Wong, "Elderly Persons' Perception and Acceptance of Using Wireless Sensor Networks to Assist Healthcare," International Journal of Medical Informatics, Vol. 78, No. 12, 2009, pp. 788-801. doi:10.1016/j.ijmedinf.2009.08.001

[30] W. C. Mann, T. Marchant, M. Tomita, L. Fraas and K. Stanton, "Elder Acceptance of Health Monitoring Devices in the Home," Care Management Journals, Vol. 3, No. 2, 2002, pp. 91-98.

[31] J. Virkki and L. Chen, "Personal Perspectives: Individual Privacy in the IOT," Advances in Internet of Things, Vol. 3, No. 2, 2013, pp. 21-26. doi:10.4236/ait.2013.32003 